\title{
Perhitungan Perkiraan Umur Transformator Akibat Pengaruh Pembebanan Dan Suhu Lingkungan
}

\author{
Setyo Adi Nugroho ${ }^{1}$, Arif Johar Taufiq ${ }^{2}$, Dian Nova Kusuma Hardani ${ }^{3}$ \\ Program Studi S1 Teknik Elektro, Universitas Muhammadiyah Purwokerto \\ Fakultas Teknik dan Sains, Universitas Muhammadiyah Purwokerto
}

\section{Informasi Makalah}

Dikirim, 23 Februari 2019

Direvisi, 1 Juli 2019

Diterima,

\section{Kata Kunci:}

pembebanan transformator suhu sekitar (ambient temperature)

susut umur transformator

\begin{abstract}
INTISARI
Transformator daya adalah peralatan penting pada sistem tenaga listrik khususnya pada penyaluran energi listrik. Dalam penyaluran energi listrik keberadaannya sangat berpengaruh terhadap kontinuitas pelayanan. Salah satu faktor yang mempengaruhi umur pemakaian transformator adalah panas yang timbul akibat pembebanan transformator dan suhu sekitar (ambient temperature). Pada penelitian ini dilakukan sebuah perhitungan dan analisis pengaruh pembebanan terhadap susut umur transformator daya pada PT. SUMBER SEGARA PRIMADAYA unit 1 . Berdasarkan hasil dari penelitian ini diperoleh penyusutan umur transformator terbesar yaitu 0,197 per unit dengan perkiraan sisa umur sebesar 48,27 tahun dan penyusutan umur transformator terkecil yaitu 0,035 per unit dengan perkiraan sisa umur sebesar 266,89 tahun. Nilai perkiraan sisa umur tersebut masih diatas standarnya yaitu 20,55 tahun berdasarkan standar IEEE C57.91 1999, dengan mengetahui perkiraan sisa umur transformator tersebut maka dapat mencegah kerusakan dengan mengganti transformator sebelum terjadi kerusakan sehingga kontinuitas pelayanan tetap terjaga.
\end{abstract}

\section{Keyword:}

transformer load ambient temperature transformer shortening age

\begin{abstract}
Power transformer is essential equipment on power system especially in the distribution of electrical energy. In the distribution of electrical energy, transformer existence is very influential towards the continuity of service. One of the factors that affect the condition of the transformer is the heat caused by transformer load and ambient temperature. In this research, a calculation and analysis of the effect of loading towards the age of transformer power is conducted at PT SUMBER SEGARA unit 1. Based on the results of this study, the largest transformer age shrinkage was 0.197 per unit with an estimated life span of 48.27 years and shrinkage of the smallest transformer age of 0.035 per unit with an estimated life span of 266.89 years. The estimated value of the remaining life is still above the standard of 20.55 years based on the IEEE C57.91 standard 1999, by knowing the estimated remaining life of the transformer it can prevent damage by replacing the transformer before damage occurs so that the continuity of service is maintained.
\end{abstract}

\section{Korespondensi Penulis:}

Setyo Adi Nugroho

Program Studi S1 Teknik Elektro

Universitas Muhammadiyah Purwokerto

Jl. Raya Dukuh Waluh Purwokerto, 53182

Email: setyo0623@gmail.com 


\section{PENDAHULUAN}

Transformator adalah suatu alat listrik yang dapat memindahkan dan mengubah energi listrik dari satu atau lebih rangkaian listrik ke rangkaian listrik yang lain, melalui suatu gandengan magnet berdasarkan prinsip induksi-elektromagnet. Penggunaan transformator dalam sistem tenaga memungkinkan terpilihnya tegangan yang sesuai dan ekonomis [1].

Dalam operasi penyaluran tenaga listrik, transformator dapat dikatakan jantung dari transmisi dan distribusi. Dalam kondisi ini diharapkan transformator dapat bekerja secara terus menerus. Mengingat kerja keras dari suatu transformator seperti itu, maka penggunaannya sangat perlu diperhatikan. Mulai dari pembeban transformator, suhu minyak transformator, suhu kumparan transformator, posisi tap dan lain sebagainya. Hal ini dimaksudkan agar penggunaannya tidak melebihi parameter yang telah ditentukan, sehingga transformator daya dapat bekerja secara optimal dan mencegah susut umur dari transformator itu sendiri.

Pembebanan pada transformator daya berpengaruh terhadap temperatur dari belitan transformator daya tersebut yang berdampak pada naiknya temperatur top oil transformator. Hal tersebut menyebabkan laju penuaan yang semakin tinggi. Peristiwa tersebut dipengaruhi juga oleh suhu lingkungan (ambient temperature), berdasarkan SPLN : 17 suhu lingkungan (ambient temperature) yang diijinkan tidak boleh lebih dari $30^{\circ} \mathrm{C}$ [2].

Ada beberapa upaya untuk menjaga suhu transformator tetap stabil yaitu dengan berbagai jenis metode pendinginan antara lain ONAN, ONAF, OFAF, dan ODAF [3].

\section{METODE PENELITIAN}

\subsection{Waktu dan Tempat Penelitian}

Penelitian ini dilaksanakan selama tujuh hari mulai tanggal 8 Januari 2018 - 14 Januari 2018 pada transformator daya unit 1 PT. Sumber Segara Primadaya.

\subsection{Prosedur Penelitian dan Analisis}

\section{a. Teknik Pengambilan Data}

Data dari transformator yaitu pembebanan, suhu kumparan, suhu minyak diambil pada pukul $00.00-$ 23.00 WIB, sedangkan data dari suhu lingkungan (ambient temperature) diperoleh dari Badan Meteorologi, Klimatologi dan Geofisika (BMKG) pada waktu yang sama.

\section{b. Analisis Data}

Dari data yang sudah diperoleh maka dapat dilakukan perhitungan penurunan umur transformator dengan menggunakan persamaan-persamaan yang dikeluarkan oleh IEC melalui standar IEC 60076-7 [3]. Adapun langkah dalam menghitung susut umur transformator sebagai berikut.

1. Menghitung Temperatur Hotspot

a. Sirkulasi Minyak Alami

$\llbracket \Delta \Theta \rrbracket \_c r($ alami $)=\llbracket \Delta \Theta \rrbracket \_b r+1,3 . \llbracket \Delta \Theta \rrbracket \_W O$

Keterangan :

$\Delta$ Өcr(alami) $=$ Temperatur hotspot $\left({ }^{\circ} \mathrm{C}\right)$

$\Delta$ Obr $\quad=\operatorname{Suhu}\left(55^{\circ} \mathrm{C}\right.$ untuk ON, dan $40^{\circ} \mathrm{C}$ untuk OF $)$

$\Delta \Theta \mathrm{WO}=$ Perbedaan antara kenaikan temperatur rata-rata kumparan dengan kenaikan temperatur rata-rata minyak 
b. Sirkulasi Minyak Paksaan

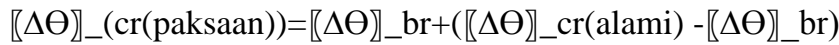

Keterangan :

$\Delta \Theta \operatorname{cr}($ paksaan $) \quad=$ Temperatur hotspot $\left({ }^{\circ} \mathrm{C}\right)$

$\Delta$ Obr $\quad=$ Suhu $\left(55^{\circ} \mathrm{C}\right.$ untuk $\mathrm{ON}$, dan $40{ }^{\circ} \mathrm{C}$ untuk OF $)$

$\Delta$ Ocr(alami) $\quad=$ Kenaikan temperatur hotspot $\left({ }^{\circ} \mathrm{C}\right)$

2. Menghitung Kenaikan Temperatur Top Oil

a. Beban Stabil

$$
\Delta \theta_{b(\text { stabil })}=\Delta \theta_{b r}\left(\frac{1+d \cdot k^{2}}{1+d}\right)^{x}
$$

Keterangan :

$$
\begin{array}{ll}
\Delta \theta_{b(\text { stabil })} & =\text { Kenaikan temperatur top oil }\left({ }^{\circ} \mathrm{C}\right) \\
\mathrm{K} & =\text { Ratio pembebanan } \\
\mathrm{d} & =(\text { Rugi }- \text { rugi daya pada pengenal }) /(\text { Rugi beban nol }) \\
\mathrm{X} & =\text { Konstanta }(0,9 \text { untuk ONAN dan ONAF; } 1,0 \text { untuk OFAF dan OFWF }) \\
\Delta \Theta b r & =\text { Suhu }\left(55^{\circ} \mathrm{C} \text { untuk ON dan } 40^{\circ} \mathrm{C} \text { untuk OF }\right)
\end{array}
$$

b. Beban Berubah

$$
\Delta \theta_{\text {b(berubah })}=\Delta \theta_{o n_{(n-1)}}+\left(\Delta \theta_{b(\text { stabil })}-\Delta \theta_{o(n-1)}\right) \cdot\left(1-e^{\frac{-t}{\tau}}\right)
$$

Keterangan :

$\Delta \theta_{\text {b(berubah })}=$ Kenaikan temperatur top oil $\left({ }^{\circ} \mathrm{C}\right)$

$\Delta$ Өon $(\mathrm{n}-1)=$ Kenaikan temperatur awal minyak $\left({ }^{\circ} \mathrm{C}\right)$

$\Delta \Theta b($ stabil $)=$ Kenaikan temperatur akhir minyak yang telah distabilkan, berhubungan dengan beban seperti dihitung dalam sub bab sebelumnya $\left({ }^{\circ} \mathrm{C}\right)$

$\tau \quad=$ Konstanta waktu minyak dalam jam (3 untuk ONAN dan ONAF; 2 untuk OFAF dan OFWF)

$\mathrm{t} \quad=$ Waktu dalam jam

3. Menghitung Kenaikan Temperatur Hotspot

a. Beban Stabil

$$
\Delta \theta_{c(\text { stabil })}=\Delta \theta_{b r}+\left(\Delta \theta_{c r(a l a m i)}-\Delta \theta_{b r}\right) k^{2 \cdot y}
$$

Keterangan :

$\Delta \theta_{c(\text { stabil })}=$ Kenaikan temperatur hotspot $\left({ }^{\circ} \mathrm{C}\right)$

$\Delta \theta_{\text {cr }(\text { alami })}=$ Temperatur hotspot $\left({ }^{\circ} \mathrm{C}\right)$

$\mathrm{K}=$ Ratio pembebanan

$\mathrm{y}=$ Konstanta $(0,8$ untuk ONAN dan ONAF; 0,9 untuk OFAF dan OFWF)

$\Delta$ Obr $\quad=$ Suhu $\left(55^{\circ} \mathrm{C}\right.$ untuk $\mathrm{ON}$ dan $40{ }^{\circ} \mathrm{C}$ untuk OF $)$

b. Beban Berubah

$\theta_{c(\text { berubah })}=\theta_{a}+\Delta \theta_{b(\text { berubah })}+\Delta \theta_{t d}$

Keterangan :

Өc $($ berubah $)=$ Kenaikan temperatur hotspot $\left({ }^{\circ} \mathrm{C}\right)$

$\mathrm{\Theta a}=$ Temperatur ambient (suhu lingkungan sekitar) $\left({ }^{\circ} \mathrm{C}\right)$

$\Delta \Theta b$ (berubah) $=$ Kenaikan temperatur top oil $\left({ }^{\circ} \mathrm{C}\right)$

$\Delta$ Otd $\quad=$ Selisih temperatur antara hotspot dengan top oil $\left({ }^{\circ} \mathrm{C}\right)$

4. Selisih Temperatur antara Hotspot dengan Top Oil

$$
\Delta \theta_{t d}=\left(\Delta \theta_{\text {cr(alami } / \text { paksaan })}-\Delta \theta_{b r}\right) k^{2 \cdot y}
$$




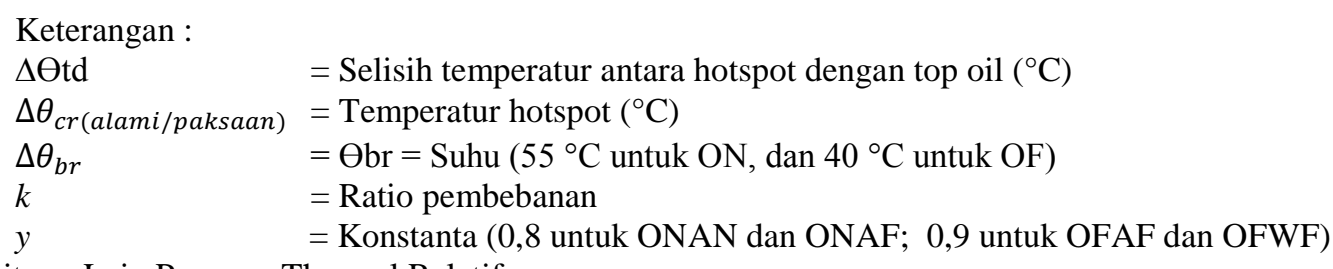

5. Menghitung Laju Penuaan Thermal Relatif

$V=10^{\left(\theta_{C^{-}} 98\right) / 19,93}$

Keterangan :

$\mathrm{V}=$ Nilai relatif dari umur pemakaian

Өcr $=98^{\circ} \mathrm{C}$ menurut publikasi IEC 76 (1967)

6. Perhitungan Pengurangan Umur Transformator

$L=\frac{1}{3 . T} \cdot\left\{V_{0}+\sum 4 V_{\text {odd }}+\sum 2 V_{\text {even }}+V_{n}\right\}$

Keterangan :

$\mathrm{L} \quad$ = Susut umur (per unit)

$=$ Waktu

Vodd, Veven = Laju penuaan thermal relatif.

Vodd untuk nilai V ganjil, Veven untuk nilai V genap.

7. Perhitungan Perkiraan Sisa Umur Transformator

$n=\frac{\text { Umur dasar }(\text { tahun })-\text { lama transformator sudah dipakai }(\text { tahun })}{\text { susut umur transformator }(\text { per unit })}$

\section{HASIL DAN PEMBAHASAN}

Pada penelitian yang telah dilakukan selama tujuh hari (8 Januari - 14 Januari 2018) di PT. Sumber Segara Primadaya unit 1 diperoleh data pembebanan transformator serta data suhu transformator. Selain data pembebanan transformator dan data suhu transfomator, dibutuhkan juga data suhu lingkungan (ambient temperature) di PT. SUMBER SEGARA PRIMADAYA yang di peroleh dari Badan Meteorologi, Klimatologi, dan Geofisika. Data lengkap ditunjukkan pada Tabel 3.1 dan Tabel 3.2 berikut.

Tabel 3.1. Data Pembebanan Transformator Daya Unit 1 PT. Sumber Segara Primadaya

\begin{tabular}{cccc}
\hline Hari/Tanggal & $\begin{array}{c}\text { Daya Terpasang } \\
(\mathbf{M W})\end{array}$ & $\begin{array}{c}\text { Daya Terpakai } \\
(\mathbf{M W})\end{array}$ & $\begin{array}{c}\text { Persentase Pembebanan } \\
(\boldsymbol{\%})\end{array}$ \\
\hline Senin/8 Januari 2018 & 300 & 209,66 & 69,88 \\
Selasa/9 Januari 2018 & 300 & 188,86 & 62,95 \\
Rabu/10 Januari 2018 & 300 & 240,20 & 80,06 \\
Kamis/11 Januari 2018 & 300 & 236,46 & 78,82 \\
Jum'at/12 Januari 2018 & 300 & 228,99 & 76,33 \\
Sabtu/13 Januari 2018 & 300 & 174,26 & 58,08 \\
Minggu/14 Januari 2018 & 300 & 171,01 & 57 \\
\hline
\end{tabular}

Halaman Web JRRE : http://jurnalnasional.ump.ac.id/index.php/JRRE 
Tabel 3.2. Data Suhu Minyak, Suhu Kumparan, dan Suhu Lingkungan

\begin{tabular}{cccc}
\hline Hari/Tanggal & Suhu Kumparan $\left({ }^{\circ} \mathbf{C}\right)$ & Suhu Minyak $\left({ }^{\circ} \mathbf{C}\right)$ & Suhu Lingkungan $\left({ }^{\circ} \mathbf{C}\right)$ \\
\hline Senin/8 Januari 2018 & 48,84 & 44,41 & 31,8 \\
Selasa/9 Januari 2018 & 47,90 & 43,88 & 27,1 \\
Rabu/10 Januari 2018 & 53,76 & 47,96 & 30,8 \\
Kamis/11 Januari 2018 & 53,83 & 48,05 & 31,5 \\
Jum'at/12 Januari 2018 & 53,97 & 48,12 & 29 \\
Sabtu/13 Januari 2018 & 47,54 & 44,08 & 33,9 \\
Minggu/14 Januari 2018 & 45,72 & 42,59 & 32,8 \\
\hline
\end{tabular}

Persamaan-persamaan yang digunakan untuk perhitungan usia transformator digunakan persamaan (1) sampai dengan persamaan (10), sehingga diperoleh hasil yang ditunjukkan pada Tabel 3.3 berikut.

Tabel 3.3. Hasil Perhitungan Susut Umur Transformator

\begin{tabular}{cccccc}
\hline No. & Persentase Pembebanan & K & V & L & Sisa Umur (tahun) \\
\hline 1 & 69,88 & 0,69 & 0,066 & 0,103 & 92,41 \\
2 & 62,95 & 0,62 & 0,026 & 0,061 & 156,56 \\
3 & 80,06 & 0,8 & 0,121 & 0,171 & 55,59 \\
4 & 78,82 & 0,78 & 0,121 & 0,197 & 48,27 \\
5 & 76,33 & 0,76 & 0,078 & 0,135 & 70,70 \\
6 & 58,08 & 0,58 & 0,044 & 0,048 & 198,05 \\
7 & 57 & 0,57 & 0,036 & 0,035 & 266,89 \\
\hline
\end{tabular}

Keterangan :

$\mathrm{K}=$ Ratio pembebanan

$\mathrm{V}=$ Laju penuaan thermal relatif

$\mathrm{L}=$ Perkiraan susut umur transformator daya

Jika diubah dalam bentuk grafik, maka diperoleh hasil seperti ditunjukkan pada Gambar 1 sebagai berikut.

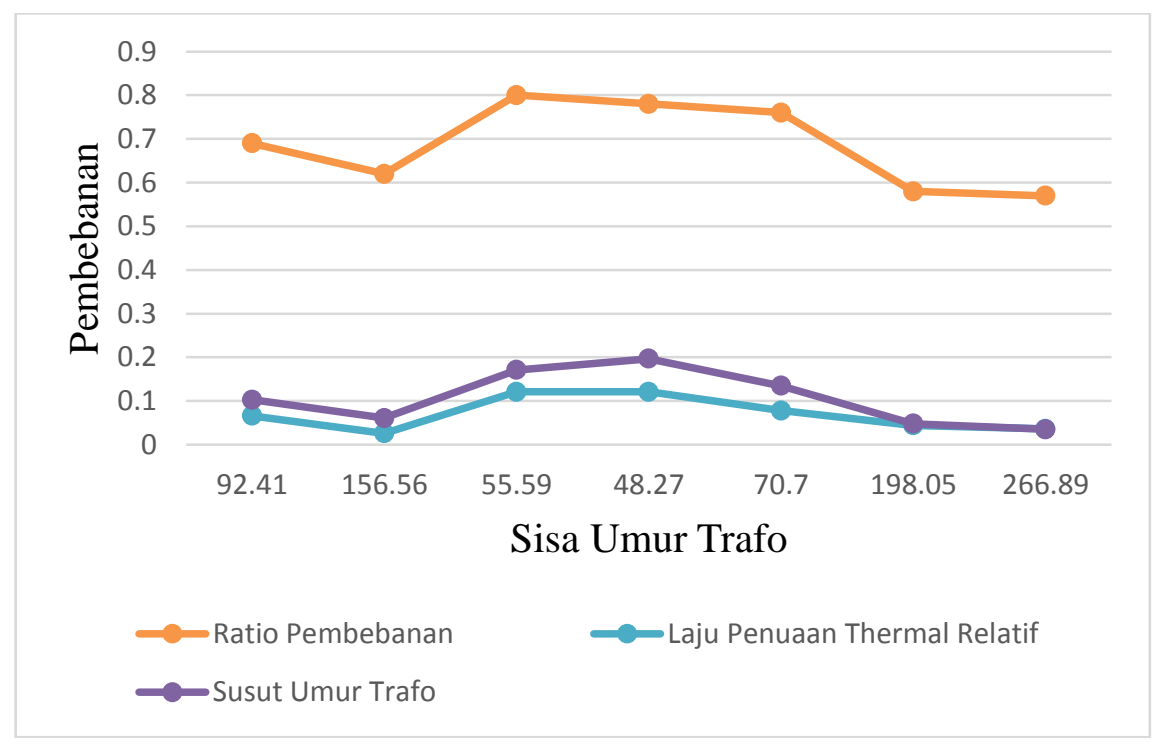

Gambar 3.1. Grafik Susut Umur Trafo 
Dari grafik pada Gambar 3.1 di atas dapat diketahui bahwa pembebanan yang lebih rendah dari daya terpasang akan mengakibatkan nilai laju penuaan thermal (V) yang rendah dan nilai susut umur transformator (L) yang rendah. Sedangkan pembebanan yang semakin tinggi akan mengakibatkan nilai laju penuaan thermal (V) dan nilai susut umur transformator (L) yang tinggi pula. Pengaruh suhu sekitar atau ambient temperature terhadap susut umur transformator sangat berpengaruh, karena pada umumnya suhu sekitar untuk transformator berkisar $20^{\circ} \mathrm{C}$ sampai $38^{\circ} \mathrm{C}$ (IEC 354). Temperatur sekitar atau ambient temperature menentukan perubahan temperatur hotspot. Semakin besar temperatur sekitar maka semakin besar temperatur hotspot, begitu pula sebaliknya.

\subsection{Analisis Umur dan Pembebanan Transformator}

Pembebanan transformator adalah besar kecilnya beban yang harus dipikul untuk memenuhi kebutuhan konsumen tenaga listrik. Pada Tabel 3.3 dapat dilihat bahwa besarnya faktor pembebanan (K) berbanding lurus dengan sisa umur transformator.

Pembebanan transformator daya yang semakin tinggi akan menyebabkan suhu kumparan dan minyak transformator semakin tinggi, sehingga berpengaruh terhadap temperatur hotspot. Selain pembebanan, suhu lingkungan (ambient temperature) juga sangat berpengaruh terhadap kenaikan temperatur hotspot.

Temperatur hotspot yang semakin tinggi mengakibatkan laju penuaan thermal relatif yang semakin tinggi, sehingga akan mengurangi umur operasional dari transformator daya.

Susut umur transformator (L) paling besar yaitu 0,197 per unit, dengan rasio pembebanan sebesar 78,82. Suhu lingkungan (ambient temperature) sebesar $31,5^{\circ} \mathrm{C}$ dan suhu minyak bagian atas (temperature top oil) sebesar $33,56^{\circ} \mathrm{C}$. Sedangkan susut umur transformator (L) paling kecil yaitu 0,03 per unit, dengan rasio pembebanan sebesar 57. Suhu lingkungan (ambient temperature) sebesar $32,8^{\circ} \mathrm{C}$ dan suhu minyak bagian atas (temperature top oil) sebesar $29,67^{\circ} \mathrm{C}$.

\section{KESIMPULAN}

Berdasarkan perhitungan dan analisis yang telah dilakukan, maka dapat diperoleh kesimpulan sebagai berikut.

a. Suhu kumparan dan minyak transformator berbanding lurus dengan pembebanan transformator daya. Semakin tinggi nilai pembebanan transformator daya maka suhu kumparan dan minyak semakin tinggi pula juga sebaliknya.

b. Nilai kenaikan temperatur hotspot adalah parameter penting untuk memperoleh perkiraan susut umur transformator. Nilai kenaikan temperatur hotspot dipengaruhi oleh perubahan suhu lingkungan (ambient temperature) dan perubahan suhu minyak bagian atas (top oil temperature).

c. Susut umur transformator dipengaruhi oleh penuaan isolasi belitan dan minyak transformator yang diakibatkan oleh pembebanan transformator dan juga suhu lingkungan sekitar (ambient temperature).

d. Semakin tinggi pembebanan maka semakin besar nilai susut umur dari transformator tersebut.

\section{DAFTAR PUSTAKA}

[1] Zuhal., “Dasar Tenaga Listrik”, ITB, 1991.

[2] Sigid, Purnama., “Analisa Pengaruh Pembebanan terhadap Susut Umur Transformator Tenaga”, Universitas Diponegoro, 2011.

[3] Ishaq M. Taufiq., “Transformer Hotspot Temperature Calculation Using IEEE Loading Guide”, Manchester. University of Manchester, 2015.

[4] IEC 60076., "Power Transformer", IEC Publication, 1976.

Halaman Web JRRE : http://jurnalnasional.ump.ac.id/index.php/JRRE 